\title{
ÂNGELA DAVIS: \\ DOR E OPRESSÃO DA MULHER EM SUAS RESISTÊNCIAS E LUTAS HISTÓRICAS
}

\author{
ÂNGELA DAVIS: \\ PAIN AND OPPRESSION OF THE WOMAN IN HER RESISTANCE AND \\ HISTORICAL STRUGGLES
}

\author{
Verônica Pacheco de Oliveira Azeredo ${ }^{1}$ \\ Ive Oliveira Campolina Azeredo ${ }^{2}$ \\ Maria Lúcia Silva Brandão
}

\begin{abstract}
RESUMO
Este ensaio apresenta aspectos relevantes apontados por Ângela Davis, em sua obra: Mulher, Raça e Classe, e sua importância para a desmistificação da escravidão como processo encerrado nos EUA em 1863. Destaca a contribuição teórico-analítica da autora em questão que evidencia a combinação das opressões de raça, gênero e classe em seus diferentes desdobramentos antes e após a abolição. Tomando a obra como referência, discute, ainda, temas como racismo, gênero, sexismo e feminismo negro. Busca relacionar as questões apresentadas com o movimento feminista no Brasil em seu viés étnico-racial.
\end{abstract}

Palavras chaves: Gênero. Racismo. Classe, Feminismo Negro.

\begin{abstract}
This article presents relevant aspects indicated by Angela Davis in her work: Woman, Race and Class, and its importance for the demystification of slavery as a process ended in the USA in 1863. It emphasizes the theoretical-analytical contribution of the author in question, showing the combination of the oppressions of race, gender, and class in their different developments before and after abolition. Taking the work as a reference, the essay also discusses themes such as racism, gender, sexism and black feminism. It seeks to relate the issues presented to the feminist movement in Brazil in its ethnoracial bias.
\end{abstract}

\footnotetext{
${ }^{1}$ Atualmente é Doutoranda em Educação pela Faculdade de Educação da Universidade Federal de Minas GeraisMestre em Estética e Filosofia da Arte -UFOP. Professora de Filosofia e Filosofia da Educação do Centro Universitário de Minas Gerais- UNILESTE -MG. E-mail: vazeredo.21@gmail.com

${ }^{2}$ Mestre em Administração com concentração na área Pública no PPGADM/UFV. Graduada em Enfermagem pela Universidade Federal de Viçosa.
} 


\title{
Debates Insubmissos
}

Revista

Keywords: Gender. Racism. Class. Black Feminism.

\section{DIVERSAS, MÚLTIPLAS E SINGULARES SÃO AS HISTÓRIAS DAS MULHERES}

\author{
A minha voz ainda \\ ecoa versos perplexos \\ com rimas de sangue \\ e fome. \\ Conceição Evaristo
}

No século XXI, o processo civilizatório enfrenta conflitos sociais decorrentes das desigualdades sociais, de gênero, raça, classe e, também, pelo reconhecimento das minorias que, gradativamente, se reconhecem como sujeitos de direitos. A luta das mulheres pela igualdade de gênero e o combate ao feminicídio ganha forças em todos os continentes. Associado ao direito ao saber, ao trabalho, à participação na política e ao direito civil, as mulheres contemporâneas exigem, inclusive, o direito ao seu corpo. Reinvindicação de longos anos, pois o corpo feminino, historicamente, pertenceu aos homens, à igreja e às determinações culturais. Tais reivindicações impulsionaram o ativismo feminino que " $[$...] nos anos 1980, na França e em quase todo o mundo ocidental, desenvolvem-se as lutas pela penalização do estupro, do assédio sexual no trabalho, do incesto, imprescritível, das lutas pela proteção das mulheres submetidas a maus-tratos físicos" (PERROT, 2017, p. 161).

Desde então, mulheres operárias, camponesas, intelectuais continuam manifestando e lutando em busca da equidade entre os sexos e do reconhecimento das diferenças, dentre essas, a de ser mulher branca e ser mulher negra. $\mathrm{O}$ discurso hegemônico, eurocêntrico do sujeito universal se enfraqueceu, pois muitas mulheres "viraram o barco" e não se reconhecem mais no modelo universalizante construído e mantido culturalmente até os dias atuais. A tentativa de silenciar, historicamente, as mulheres, não apagou as lutas femininas que existiram e que vêm conquistando novos territórios e se fortalecendo nos espaços sociais.

Como ressalta Beauvoir (1980), o conceito de homem, criado pela sociedade europeia, não abarca a totalidade dos seres humanos. Há interesses não confessos, porém manifestos no poder de quem institui seus fundamentos e os dissemina nos espaços sociais. Integrado ao 
modelo universalizante do homem branco, é criado o conceito de mulher que também é universalizado. Nada mais equivocado, pois como nos lembram Scott (1990) e Perrot (1990, 2017) diversas, múltiplas e singulares são as histórias das mulheres em seus percursos ao longo da história, sendo inconcebível aprisioná-las em uma única referência universal e homogênea.

$\mathrm{Na}$ esteira desse raciocínio somos impelidas a sair da margem, a escavar, destacar os sentidos subjacentes presentes na criação do modelo de homem e o desdobramento da hierarquia instituída na relação entre os sexos. Penetrarmos na análise do conceito de mulher e suas implicações que englobam a orientação sexual, opções religiosas, questões de raça/etnia, entre outros, sem negligenciarmos a abordagem sobre a diferenciação entre mulheres brancas e mulheres negras.

Para tanto, trazemos entre estudiosas do tema que têm evidenciado as lutas e descortinamentos sobre as trajetórias femininas, Ângela Davis, intelectual negra, que se aprofundou na investigação sobre a mulher negra nos Estados Unidos da América. Em sua obra $^{3}$, Davis retrata a situação dos negros nos EUA no período da escravatura até a abolição em 1863 e seus reflexos na sociedade. Simultaneamente, nos convoca a refletir sobre o racismo, o machismo, as relações de classe e o caminho percorrido pelas mulheres negras na política, na cultura, na produção de novas análises e questionamentos.

Nessa reflexão, o entendimento da universalidade na definição dos conceitos homem e mulher fragiliza-se diante da diversidade cultural, sexual, política. De forma mais pontual, os fatores raciais/étnicos, socioeconômicos e de gênero que se destacam na obra da autora, não podem ser negligenciados, uma vez que são preponderantes para a desconstrução do conceito universalizante de mulher.

Considerando, ainda, nosso objetivo de apresentar a produção sobre a mulher negra realizada por Ângela Davis, cabe também indagar: mulheres brancas e mulheres negras têm sido abordadas e julgadas ao longo da história da mesma forma? Podem ser consideradas

\footnotetext{
${ }^{3}$ A obra "Mulher, raça e classe" foi publicada em 1982 com tradução livre no Brasil em 2013, sendo publicada pela Boitempo em 2016.
} 


\section{nexstate \\ Debates Insubmissos}

iguais, independentemente dos fatores culturais, étnico-raciais e socioeconômicos inerentes às suas trajetórias e histórias de vida?

O sistema escravista tornou evidente que as experiências vividas pelas mulheres negras não condiziam com o conceito de sexo frágil e que os homens negros não podiam ser chefes de família. Portanto, os discursos de sexo frágil e chefe de família não se destinavam aos negros e negras, embora a universalização desses conceitos se aplique, indistintamente, a todos nas sociedades.

Nesse aspecto, o discurso sobre a fragilidade feminina nos leva a questionar os seus sentidos e propósitos propagados ao longo da história como único e universal. Sobre essa narrativa cabe indagar a quem essa fragilidade atende e beneficia? Se esse discurso não estaria reafirmando uma assimetria e hierarquia construída e reforçada nas relações de gênero nas mais diferentes realidades sociais?

Em sua produção, Ângela Davis (2016) ressalta que o suposto conceito de fragilidade feminina e de rainha do lar, embora questionável e falho, se encaixava às experiências e realidade atribuídas às mulheres brancas e não às mulheres negras, uma vez que a história das mulheres negras se caracterizou pelo trabalho bruto, pesado antes e após a abolição. De amas e escravas dos brancos, tornaram-se via de regra, empregadas domésticas, serviçais a exercer qualquer outra função subalternada que lhes garantisse sua sobrevivência e de sua família. Sobre essa questão, vale lembrar que, as condições apontadas pela autora extrapolam limites temporais e territoriais para se verificarem em outras sociedades, diferentes da analisada por ela, como a brasileira,

Quando falamos em romper com o mito da rainha do lar, da musa idolatrada dos poetas, de que mulheres estamos falando? As mulheres negras fazem parte de um contingente de mulheres que não são rainhas de nada, que são retratadas como antimusas da sociedade brasileira, porque o modelo estético de mulher é a mulher branca. Quando falamos em garantir as mesmas oportunidades para homens e mulheres no mercado de trabalho, estamos garantindo emprego para que tipo de mulher? Fazemos parte de um contingente de mulheres para as quais os anúncios de emprego destacam a frase: "Exige-se boa aparência" (CARNEIRO, 2011, p. 2). 
No que diz respeito à produção acadêmica sobre as mulheres, não é necessário muito esforço para entendermos que os desdobramentos do discurso da universalidade, atingiu, também, o interior da categoria mulher, mesmo entre as estudiosas da área.

$\mathrm{Na}$ sua maioria, as tentativas das(os) historiadoras(es) de teorizar sobre gênero não fugiram dos quadros tradicionais das ciências sociais: elas(es) utilizaram as formulações antigas que propõem explicações causais universais. Estas teorias tiveram, no melhor dos casos, um caráter limitado porque elas tendem a incluir generalizações reducionistas (SCOTT, 1990, p. 5- 6).

Dessa forma, embora incialmente viciada, porque homogênea, a abordagem sobre as mulheres em seus mais diferentes aspectos e dimensões, não pode ser outra, ou seja: múltipla e diversa. Ainda é importante ponderar que as produções referentes às mulheres e ao movimento feminista no Brasil passaram pelo mesmo processo de universalização e homogeneidade, consideradas como recentes, tendo como marco os anos 1980 do século XX. A partir desse marco e do desdobramento do movimento feminista brasileiro, a militância negra ganha visibilidade em relação ao discurso homogêneo e hegemônico sobre as mulheres brancas não considerando, neste movimento, principalmente, a diversidade e a multiplicidade étnica das histórias e trajetórias das mulheres brasileiras.

\section{2. “A VOZ DE MINHA AVÓ ECOOU OBEDIÊNCIA AOS BRANCOS-DONOS DE TUDO"4}

Ao fincar raízes no debate sobre as mulheres e o racismo, a filósofa americana demarcou o território da mulher negra na política, na cultura, na produção de novas concepções sobre elas. A questão do gênero discutida no interior do movimento negro foi abordada em suas diferentes dimensões, sendo uma delas, o próprio comportamento do homem negro em relação à mulher negra que, também, era e ainda hoje é submetida à desigualdade e opressão.

O elemento constitutivo de sua obra está na luta para que os negros e as negras sejam efetivamente reconhecidos e integrados com igualdade de direitos nas sociedades contemporâneas. A autora destaca, entre outros aspectos, o poder da hierarquia presente nas ${ }^{4}$ Este título e os demais a serem apresentados nas sessões seguintes são de autoria de Conceição Evaristo, em seu
livro "Poemas da Recordação e Outros Movimentos", do poema Vozes-Mulher, 2017, p. 10- 11. 
relações de gênero reivindicando o fim da exclusividade do poder atribuído e exercido pelos homens da comunidade negra, para ser gestado pelo grupo e compartilhado coletivamente. Entretanto, reconhece que para a transformação dessa realidade, torna-se essencial o autorreconhecimento do grupo e sua conscientização sobre a existência das diferenças, desigualdades e injustiças presentes nas relações de gênero, para fomentar em seus membros o desejo de transformá-las.

O machismo e o racismo, muitas vezes manifestados de forma velada, instigaram e reforçaram a marginalização feminina. Como gesto de interrupção, o lugar da mulher negra foi demarcado para se incorporar ao debate social, deslocando-a da marginalidade e do silenciamento. Embora dura e difícil, Ribeiro (2016) defende que essa perspectiva de marginalidade que sempre atravessou o caminho das mulheres negras, serviu como elemento de fortalecimento à luta e ao movimento feminista negro.

Decorre daí a possibilidade de uma nova visibilidade da mulher negra pela sociedade, podendo ser vista e compreendida de forma mais justa e democrática, bem como os silenciamentos impostos e os desafios enfrentados, pois quando modificado o foco e a abordagem sobre ela, emerge uma nova visibilidade que propicia uma nova perspectiva para que a ela possa ser vista por sua capacidade revolucionária e de mudança como resultado de suas experiências e lutas, conforme Ribeiro (2017, p.85-92).

Como destaca Davis (2016, p. 62-82), o lugar da opressão possibilita à mulher negra pensar fortemente sobre as mudanças urgentes que precisam ser realizadas, mas não sem muita luta e coragem. Entre os seus principais desafios nessa luta, está a percepção de que se trata de histórias e universos diferentes: homem branco, mulher branca, homem negro, mulher negra. Desta maneira, muitos silêncios poderão ser rompidos para que seus sons, palavras e ações possam chegar nas diversas sociedades e penetrarem no cotidiano de outras diferentes histórias de mulheres e homens. Trata-se de uma realidade no plural com seus muitos desdobramentos e especificidades que, ainda na atualidade precisa ser compreendida.

Pesquisas e produções sobre as mulheres negras são fundamentais para pontuar o lugar da enunciação e a luta pelo seu direito de falar, ser ouvida e respeitada para entendermos e 


\title{
novist

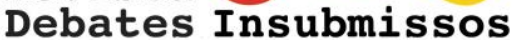

analisarmos de onde ela fala e se há privilégios velados. Consequentemente, é preciso aprimorarmos o exercício da empatia, nos deslocarmos de nós mesmos para compreendermos a dor do outro, nos colocarmos na escuta atenta, para melhor conhecer e compreender os anseios íntimos que percorrem a vida das pessoas com histórias e trajetórias diversas e distintas.

Entre a dor e a opressão, entre os avanços e recuos, a mulher negra, escrava, mas fiel ao seu desejo de igualdade, atravessava as portas, mesmo sem permissão. Entre os choros ocultos e, apesar da dor e da crueldade que a escravidão se apresentava, havia mulheres negras que não desistiram do combate. Ângela Davis (Idem, p.50) destaca Sojuner Truth, como uma delas, uma mulher negra, escrava que abalou as convicções das pessoas presentes em uma convenção feminista, em 1851, quebrando a invisibilidade que os presentes teimavam em enxergar.

Nela, diante da reivindicação feminina pelo direito ao voto, um argumento masculino colocou em xeque a capacidade das mulheres para votar, ao lembrar que elas necessitavam e dependiam dos homens até para atravessarem uma poça de água para subir em uma carruagem. Davis em sua narrativa, aponta a sabedoria, a coragem e a marca da sensibilidade cimentada no corpo da mulher negra, escrava, que ao se fazer ouvir em sua argumentação

\begin{abstract}
Olhe para mim! Olhe para os meus braços". [...] Eu lavrei, plantei, e ceifei para celeiros e nenhum homem podia ajudar-me! E não sou eu mulher? Podia trabalhar tanto e comer tanto como um homem, quando podia fazê-lo, e suportar o chicote também! E não sou eu mulher? Dei à luz a treze crianças e vi a maior parte delas serem vendidas para a escravatura, e quando chorei a minha dor de mãe, ninguém senão Jesus me ouviu! E não sou eu mulher? Se a primeira mulher que Deus fez foi forte o suficiente para virar o mundo ao contrário sozinha, estas mulheres juntas são capazes de pô-lo no lado certo. E agora que estão a pedir para fazê-lo, é melhor os homens deixá-las fazê-lo. (SOJUNER TRUTH, apud DAVIS, 2016, p.72)
\end{abstract}

Importante destacar que o episódio narrado aponta para a existência de diferenças consideráveis entre ser mulher negra, escrava e ser mulher branca, demonstrando assim, que os fatores biológicos não são suficientes para conceituar a mulher como universal. Nesse sentido, Davis destaca que o gênero, a raça e a classe social são elementos que permitem lançar outras luzes para melhor compreensão do processo da subalternização e opressão.

Embora não tenha construído o conceito de interseccionalidade, muitos estudiosos consideram a relevante contribuição da autora quanto à indissociabilidade desses três 


\section{novist \\ Debates Insubmissos}

elementos (gênero, raça e classe social) presente na obra de Davis. Essa categoria de análise foi cunhada conceitualmente há 30 anos pela jurista estadunidense, Kimberlé Crenshaw ${ }^{5}$, professora da teoria crítica de raça, no âmbito das leis antidiscriminação ao teorizar a sugestão histórica pensada pelo movimento de mulheres negras.

Neste sentido, explicita as condições adversas daquelas definidas como direito da mulher branca e da mulher negra diante das diferenças entre as realidades vividas, apontando as estruturas de poder, as formas de dominação e discriminação que ocorrem de forma implícita ou explícita nas interações humanas no cotidiano das sociedades. Denuncia, ainda, o sexismo, o machismo e o racismo, presentes, ainda hoje nas diferentes sociedades. Para ilustrar que o posicionamento da autora, não se restringe à realidade norte americana, trazemos a mesma questão sob a perspectiva da realidade brasileira

Quando falamos do mito da fragilidade feminina, que justificou historicamente a proteção paternalista dos homens sobre as mulheres, de que mulheres estamos falando? Nós, mulheres negras, fazemos parte de um contingente de mulheres, provavelmente majoritário, que nunca reconheceram em si mesmas esse mito, porque nunca fomos tratadas como frágeis. Fazemos parte de um contingente de mulheres que trabalharam durante séculos como escravas nas lavouras ou nas ruas, como vendedoras, quituteiras, prostitutas... Mulheres que não entenderam nada quando as feministas disseram que as mulheres deveriam ganhar as ruas e trabalhar! Fazemos parte de um contingente de mulheres com identidade de objeto. Ontem, a serviço de frágeis sinhazinhas e de senhores de engenho tarados (CARNEIRO, 2011, p. 01).

Na história dos negros e negras, de sua luta pela abolição e do reconhecimento como cidadãos, Davis nos permite refletir sobre o comportamento machista, racista e opressor reforçados e resultantes do sistema escravocrata existente, também, em outros países. O imaginário de inferioridade diante da raça negra, ainda, emerge nas narrativas e comportamentos do homem branco e da mulher branca. É preciso conhecer e se desarmar para conseguirmos ver e ouvir a dor do outro em suas trajetórias de vida.

A experiência das mulheres negras e escravas, ressaltada pela autora deve ser compreendida a partir dos espaços e locais de trabalho por elas ocupados e, principalmente,

\footnotetext{
${ }^{5}$ Kimberlé Williams Crenshaw é uma defensora dos direitos civis americana e uma das principais estudiosas da teoria crítica da raça.
} 


\section{Revista \\ Debates Insubmissos}

agravada pela sua vulnerabilidade diante de sua condição de gênero. À semelhança dos homens escravos, muitas trabalhavam no campo sem distinção dos serviços destinados a eles e para além dos castigos físicos e maus tratos, elas sofriam todo tipo de violência e abusos sexuais Davis (2016, p. 29).

Negros e negras eram considerados não-humanos, transportados e avaliados como uma raça inferior, resultando daí a justificativa para a não existência da igualdade entre brancos e negros. Ainda, dentro dessa estrutura social, as mulheres negras eram as que sofriam as maiores injustiças, pois além dos homens brancos e mulheres brancas, também, eram dominadas pelos homens negros. As gerações anteriores referenciadas nas bisavós e avós carregaram as marcas mais profundas, pois não tiveram ascensão social, eram subjugadas pelos "brancos-donos de tudo."

Outro aspecto apontado sobre as mulheres negras e que merece reflexão, diz respeito às narrativas decorrentes do imaginário criado sobre a performance sexual das negras como mulheres quentes e sedutoras e que ainda hoje se perpetuam. Essas representações escamoteiam, desde a época da escravidão, toda sorte de violência e abuso provenientes de seus donos e seus capatazes, de quem eram vítimas e a partir da abolição até os dias atuais, utilizadas para justificar e perpetuar esse tipo de violência.

Diante dessa questão, Carneiro (2017) destaca a presença de um imaginário construído no período colonial no Brasil, relacionado à mulher negra, que se faz presente até os dias atuais. Ainda segundo Davis (2016), havia, também, por parte dos proprietários, a supervalorização da capacidade de procriar das negras e a geração de mão de obra nova, retornando ao dono, mais lucro.

A exaltação ideológica da maternidade - tão popular durante o século XIX - não se estendia às escravas. Na verdade, aos olhos de seus proprietários, elas não são realmente mães; eram apenas instrumentos que garantiam a ampliação da força de trabalho escravo. Elas eram "reprodutoras" - animais, cujo valor monetário podia ser calculado com precisão a partir de sua capacidade de multiplicar. (DAVIS, 2016, p. 25-26).

\footnotetext{
${ }^{6}$ Conceição Evaristo, Poemas da Recordação e Outros Movimentos. Poema Vozes-Mulher, 2017, p. 11.
} 
Mesmo sendo filhos do patrão ou qualquer homem branco, os filhos das escravas eram escravos, sem que houvesse qualquer tipo responsabilização da paternidade. As escravas, não eram consideradas mães, apenas mulheres que geravam crias e seus filhos não-humanos eram vendidos como produtos, pois a vida humana negra escrava era coisificada. Essa situação arrastou-se até o término da escravidão. Além disso, no final da escravatura nos EUA, o tribunal decidiu que as escravas não teriam direito de recorrerem para recuperarem seus filhos. Em que pesem os esforços na luta dos escravos pela liberdade e dignidade, o privilégio dos brancos americanos refletia-se do mesmo modo nas decisões judiciais, na prevalência de leis injustas, nos termos de Davis (2016, p.86).

As mulheres escravas eram iguais aos homens negros dentro da comunidade escrava e resistiram à escravidão tanto quanto eles. Eram sujeitadas ao mesmo sistema rude, reconheciam a igualdade entre elas e os demais escravos. Interessante notar que, os homens brancos deixam pistas de ações para quebrar essa igualdade por meio da brutal repressão e violar as mulheres negras para colocá-las em seu devido lugar.

Embora fosse uma agressão brutal contra as mulheres, a violência e o abuso sexual não foram temas comumente abordados na literatura sobre a escravatura. Quais as razões do silenciamento diante dos abusos sexuais sofridos pelas mulheres escravas? Violar as mulheres negras não era enfoque relevante para ser denunciado e discutido? Importante indagarmos se o silenciamento sobre a violência sexual sofrida, principalmente pela mulher negra, não seria a ausência de reconhecimento do abuso cometido ou desonroso demais para ser exposto? (DAVIS, 2016, p. 192)

Nesse aspecto, deve ser ressaltado que a adoção de uma medida legal como foi a abolição da escravidão, não legitimou na mesma medida a curto e médio prazo, os direitos e a justiça para os negros, então, libertos. Mulheres, homens e crianças passaram a ser reconhecidos como sujeitos de direitos formalmente somente após a abolição. Em 1863 os negros são libertados, porém, premidos de dignidade, vinculados à pobreza e perseguições. Os homens e mulheres negras eram presos com maior facilidade, estavam ainda desprovidos dos direitos de cidadãos. 
Prevalecia o preconceito velado, o ódio oculto e o sentimento de que os negros não eram merecedores de igualdade. Estes e outros aspectos foram provenientes não apenas do período escravista, mas permaneceram e foram reforçados mesmo após decretado o seu fim. Assim, um dos aspectos relevantes da obra de Ângela Davis (2016) diz respeito à desmistificação da abolição da escravidão como determinante para o enfraquecimento e fim de sentimentos e concepções pejorativos, discriminatórias e racistas sobre a condição dos homens e mulheres negros na sociedade americana.

Além disso, a definição cristalizada de família, compreendida como universal, ocultava as desigualdades e os privilégios presentes na sociedade. Homens, mulheres e crianças negros, mesmo após a escravidão, não foram reconhecidos como sujeitos de direitos, diante da invisibilidade a eles atribuída. A autora destaca a necessidade de lançar luzes na relação opressor e oprimido no processo de resistência dos homens, mulheres e crianças negras.

Outro aspecto a ser destacado diz respeito à concepção de feminilidade que, no século XIX e por muitas décadas do século XX, enfatizava o papel da mãe cuidadora, dócil e dona de casa para seus maridos. Entretanto, as mulheres negras não se enquadravam nesse modelo que, mesmo após a abolição, sobre elas permaneciam imagens estereotipadas negativas a exemplo da sua promiscuidade que justificava o estupro pelos homens brancos. Essas e outras experiências de racismo e opressão vividos pelas mulheres negras retiravam delas qualquer atribuição de feminilidade que pudesse ser associado às mulheres brancas.

O corpo da mulher, que a sociedade aprendeu a oprimir, também revela a resistência e as lutas históricas pela liberdade e reconhecimento. Embora houvessem tentativas para as calarem, diversas vozes ecoaram. Nas primeiras décadas de 1800, Davis (2016) aponta a mobilização das mulheres brancas que se juntaram ao movimento abolicionista e demonstraram revolta e perplexidade diante dos abusos sexuais e das inúmeras formas de violência contra as mulheres negras. Apesar do reconhecimento da luta intensa de uma parcela de mulheres brancas pela abolição, a autora não deixa de ressaltar que elas não conseguiram abarcar a totalidade da condição das mulheres negras. Sem abandonar a 
denúncia da opressão patriarcal e da violação dos direitos impostos aos escravos, as mulheres brancas deixaram indícios de racismo ainda internalizados pelo modelo de sua época.

Embora tenham colaborado de forma inestimável para a campanha antiescravista, as mulheres brancas quase nunca conseguiam compreender a complexidade da situação da mulher escrava. As mulheres negras eram mulheres de fato, mas suas vivências durante a escravatura -trabalho pesado de seus companheiros, igualdade no interior da família, resistência, açoitamentos e estupros- as encorajavam a desenvolver certos traços de personalidade que as diferenciavam da maioria das mulheres brancas. (DAVIS, 2016, p. 40)

A autora menciona livros do período abolicionista, a exemplo da obra "Uncle Tom's Cabin”, de Harriet Beecher Stowe, que reuniu um vasto número de pessoas, principalmente mulheres defensoras da causa antiescravatura, porém, as personagens escravas criadas se aproximavam do ideal de seu tempo, da mulher branca americana.

Ainda sobre a participação das mulheres brancas na luta pelo fim da escravidão, Davis aponta que, em 1830, as mulheres brancas, esposas e trabalhadoras nas indústrias atuaram no movimento abolicionista. Angariaram fundos para organizarem campanhas antiescravatura. Como resultado, em 1833, nasceu a "Philadelphia Female Anti-slavery Society" (Sociedade Feminina Antiescravatura de Filadélfia). Assim, embora considerando as limitações culturais relativas ao universo feminino atribuído às mulheres negras, diversas mulheres brancas abraçaram a causa dos negros e negras e instituíram a convenção com a "Sociedade Americana Antiescravatura".

Outro relevante aspecto presente na obra de Davis, diz respeito a ações como as de Prudenc Crandall, professora em Connecticut que desafiou a sua cidade branca, aceitando jovens negras em sua escola. Diferentes formas de repressão e tentativa de subjugação ocorreram como lojistas que se recusaram a fornecer suprimentos à Miss Crandall, comportamento semelhante tiveram outros profissionais liberais da cidade, negando assistência médica e medicamentos para as estudantes negras.

Membros da comunidade chegaram a atear fogo na escola. A escola foi reerguida e a perseguição resultou em sua prisão por defender os direitos à educação para as jovens negras e por empregar uma mulher negra. Embora com resultados nefastos para ela, esse gesto 
representou uma aliança poderosa entre a luta pela libertação dos negros e negras e a embrionária batalha pelo direito das mulheres, Davis (2016, p. 52).

Importante ressaltar que é possível que as pessoas brancas que praticaram violências verbais, materiais e físicas se reconheciam e eram consideradas como pessoas de bem, cristãs, bons pais de família e boas mães. Entretanto, não se reconheciam como cidadãos com privilégios, mas apenas, pessoas brancas com direitos superiores aos negros e sentiam que seus direitos, ditos naturais, estavam ameaçados. Além da forte influência cultural, a maioria da população não possuía a consciência das prerrogativas que ocultavam seus privilégios, resultando em resistência e desinteresse na mudança de entendimento sobre os negros e negras.

Davis (2016, p. 52) adverte que mulheres brancas além de agirem pela abolição da escravatura também atuaram a favor do feminismo. Cita a pastora Quaker ${ }^{7}$ Lucretia Mott, em 1833, como uma das quatro mulheres convidadas, a acompanhar a Convenção Americana Antiescravatura, mas não tiveram o direito de assinar os documentos sobre as propostas e acordos realizados. Dentre as mulheres abolicionistas pioneiras, as irmãs Grinke da Carolina do Sul, Sarah e Angelina ${ }^{8}$, foram as que mais consistentemente ligaram a questão da escravatura à opressão das mulheres. Como conferencistas, se sentiram compelidas a defenderem os seus direitos como mulheres para serem defensoras da abolição, e dessa forma, tornavam públicas ambas as bandeiras. Ambas ressaltavam a desumanidade da escravidão, perceberam ainda, que a opressão feminina não se desvinculava da opressão de raças e que essa luta não poderia ser desmembrada. Contestaram a fala masculina de que afirmava ser antinatural que mulheres atuassem na liderança de movimentos reformistas. Insistiam elas que 'aquilo que é um direito do homem é um direito da mulher. "E então, o que a mulher poderá fazer contra a escravidão, quando ela mesma estiver subjugada ao homem e humilhada no silêncio?" (ANGELINA apud DAVIS, 2016, p. 58).

\footnotetext{
${ }^{7}$ A Sociedade de Amigos, comumente chamado Quakers, é um corpo de cristãos que se originou no século 17 na Inglaterra, sob a liderança de George Fox. Em 1988, a sociedade tinha 200.260 membros, com forte concentração nos Estados Unidos (109.000), África Oriental (45.000) e Grã-Bretanha (18.000) Quakers unir na afirmação do imediatismo do ensinamento de Cristo. Eles sustentam que os crentes recebem orientação divina de uma luz para dentro, sem o auxílio de intermediários ou ritos externos. $\underline{\text { http://mb- }}$ soft.com/believe/ttcm/quakers.htm

${ }^{8}$ Angelina (1805-1879) e Sarah Grimke (1792- 1873), nascidas em Charleston, Carolina do Sul, as irmãs Grimke eram Quakes e, desde cedo, defensoras do abolicionismo e dos direitos das mulheres.
} 
Embora difícil e sofrida, a realidade vivida pelos homens negros após a abolição norte americana, caracterizada pelas discriminações e racismo, sua condição foi diversa daquela vivida pelas mulheres negras que ainda traziam as marcas das desigualdades de gênero. Neste sentido, uma de suas principais lutas foi direcionada pelo direito ao voto, sendo ele um entre tantos outros seus direitos civis, negados, mesmo após a escravidão.

Como já afirmado, ressalta-se, também, a presença do racismo entre algumas as mulheres brancas que, em sua luta pelo direito ao voto, se julgavam com mais direitos que os homens negros. Já as mulheres negras, por serem mulheres e negras, e por isso, consideradas inferiores pelos homens e mulheres brancas e homens negros, eram enfraquecidas em sua reivindicação pelo direito ao voto.

\title{
3. “A VOZ DE MINHA MÃE ECOOU BAIXINHO REVOLTA NO FUNDO DAS COZINHAS ALHEIAS"9
}

Após o término da escravidão nos EUA, a maioria das mulheres negras permaneceu no trabalho subalternizado, doméstico ou no campo. Como já apresentado, a abolição não significou igualdade plena e acesso aos direitos civis, principalmente para as mulheres negras, vistas como inferiores por carregarem duplamente o estigma de serem mulheres e ex-escravas. Nos espaços do trabalho doméstico, a voz de revolta da mãe, ex-escrava, ecoava baixinho seu choro no fundo das cozinhas alheias, como nos lembra o fragmento do poema a seguir:

\author{
A voz de minha bisavó \\ ecoou criança nos porões do navio \\ ecoou lamentos de uma infância perdida. \\ A voz de minha avó \\ ecoou obediência \\ aos brancos-donos de tudo. \\ A voz de minha mãe \\ ecoou baixinho revolta \\ no fundo das cozinhas alheias \\ debaixo das trouxas roupagens \\ sujas dos brancos \\ pelo caminho empoeirado
}

\footnotetext{
${ }^{9}$ Conceição Evaristo, Poemas da Recordação e Outros Movimentos. poema Vozes-Mulher, 2017, p. 10.
} 


\section{Revista
Debates Insubmissos}

junto à favela.

(EVARISTO, 2017, p. 10-11)

Embora Davis tenha produzido uma obra sobre a escravidão e abolição norteamericana e considerando os diferentes territórios, a experiência vivida na sociedade brasileira, também, pelos homens e mulheres negras apresentam conotações semelhantes por se tratar, igualmente, de uma sociedade marcada pelo colonialismo, patriarcado e crueldade das práticas escravistas em seus vários desdobramentos.

O choro de quem conhecia a liberdade, mas não a igualdade de direitos, tornava-se, para as escravas libertas, um sonho silenciado mesmo após muitas gerações. Nesse sentido, fica evidente que modelos hegemonicamente cristalizados pelo capitalismo e pela sociedade patriarcal e machista não se rompem facilmente, sendo a mão de obra negra feminina atrelada à subalternização, uma vez que essas mulheres não conseguiam empregos em igualdade de condição com as mulheres brancas, além do que, para essas, a oportunidade de trabalho fosse $60 \%$ menor que o homem na mesma atividade.

A atribuição dos trabalhos considerados inferiores e submissos às mulheres negras, demonstra a continuidade da opressão presente nas relações capitalistas, marcadas pelas relações de gênero, pelo racismo e condição de classe. Os diferentes tipos de violência invisíveis e visíveis a exemplo da prática do estupro no ambiente de trabalho continuaram a existir com a conivência de muitas mulheres brancas, pertencentes a movimentos feministas que consideravam essa prática normal.

Se em muitas situações, a defesa das mulheres brancas contra o racismo se fez no e pelo movimento sufragista, em outras, mesmo neste movimento, muitas delas não percebiam o racismo velado em suas falas e comportamentos. Nesse aspecto, evidencia-se que, mesmo a militância exercida por essas mulheres nos movimentos, não seguia uma concepção e conduta uniforme e tampouco homogêneas.

Ainda, a exclusão das reivindicações das mulheres negras em alguns movimentos sufragistas, liderados pelas mulheres brancas, evidenciaram, como ressalta Davis, outra clara discriminação de cor e classe, dando origem às divisões no interior dos grupos dentro dos 
embrionários movimentos feministas, uma vez que nesses movimentos, as mulheres negras ficavam subsumidas. Lembra-nos, ainda, a autora que somente nos anos 1980 do século XX, o movimento negro conseguiu ser finalmente ressignificado e fortalecido diante da aliança entre a militância negra e a academia.

Sobre o movimento feminista liderado pelas mulheres brancas, Ribeiro (2016), também, aponta que a teoria feminista acabou incorporando o discurso de exclusão e silenciamento das mulheres negras, estruturando o discurso das mulheres brancas como dominante. Destaca a gravidade dessa lógica presente ainda na atualidade, uma vez que a invisibilidade atribuída à mulher negra dentro da pauta feminista faz com que ela não tenha seus problemas sequer nomeados.

Nesse sentido, Ribeiro defende a necessidade da construção de contradiscursos e contranarrativas que se traduzam a reivindicação não só de existência das mulheres negras, mas também a busca de alternativas emancipatórias para problemas que, durante décadas, ficaram invisibilizados nos discursos do movimento feminista.

Ainda sobre esse aspecto, cabe destacar o posicionamento de Carneiro (2011) que, do mesmo modo, defende a necessidade de outra análise e interpretação para a história das mulheres negras no Brasil, que assumiu outros contornos, distintos daqueles constituintes da história das mulheres brancas. Lembra, ainda, que o não reconhecimento dessa distinção, até hoje, têm dificultado a construção da identidade negra para muitas mulheres. Sobre o movimento negro no Brasil, a autora ressalta que

[...] as mulheres negras tiveram uma experiência histórica diferenciada que o discurso clássico sobre a opressão da mulher não tem reconhecido, assim como não tem dado conta da diferença qualitativa que o efeito da opressão sofrida teve e ainda tem na identidade feminina das mulheres negras (CARNEIRO, 2011, p. 02).

Vale destacar que um dos aspectos relevantes apontados por Davis está na desconstrução da imagem de uma sociedade racial democrática após a escravidão. Ao contrário, ela ressalta que a permanência e recrudescimento do racismo mesmo após a abolição, se fez presente de forma velada ou explícita, enfraquecendo movimentos em prol das lutas por igualdade de direitos. Nesse sentido, suas considerações reverberaram em outros 


\section{Revista \\ Debates Insubmissos}

lugares, a exemplo do Brasil, diante da constatação de situações análogas, embora considerando-se a especificidade de cada realidade.

Sobre elas, Carneiro (2011) defende ser o racismo o principal eixo articulador do movimento feminista negro diante de seu impacto sobre as relações de gênero, uma vez que ele determina a própria hierarquia de gênero no interior dessa categoria. Sem desvinculá-lo das questões de classe e gênero, nele imbricadas, ela acrescenta:

O racismo estabelece a inferioridade social dos segmentos negros da população em geral e das mulheres negras em particular, operando ademais como fator de divisão na luta das mulheres pelos privilégios que se instituem para as mulheres brancas. Nessa perspectiva, a luta das mulheres negras contra a opressão de gênero e de raça vem desenhando novos contornos para a ação política feminista e anti-racista, enriquecendo tanto a discussão da questão racial, como a questão de gênero na sociedade brasileira. (CARNEIRO, 2011, p. 02)

Os avanços sociais e a diminuição da desigualdade conquistados ao longo da história do movimento feminista são frutos de enfrentamentos da militância das mulheres que, em sua trajetória, pressionaram, tensionaram e conquistaram. Por isso, repreender a fala do outro, ou reprimi-la resulta no impedimento da escuta sobre a sua verdade diferente e diversa daquelas hegemonicamente consideradas na sociedade e, assim, no reforço de concepções equivocadas, como a naturalização da desigualdade de gênero, de raça e de classe tão bem destacados por Ângela Davis.

Djamila Ribeiro ${ }^{10}$ afirma, ainda, que o ódio é, também, o medo dos avanços já conquistados pelas pessoas consideradas mais frágeis política, profissional e economicamente associado e o temor está na possibilidade de avançarem cada vez mais. Afinal, já "ganharam muito". Homens e mulheres experimentam o mundo de forma diferente. Além disso, é preciso atenção ao lugar da enunciação, pois não falamos desvinculados de nossa história raça, classe social e gênero.

\footnotetext{
10 Seus depoimentos foram gravados no programa Saia Justa, canal GNT, disponível no YouTube (10.nov.17) aborda “O lugar da fala” e em entrevista sobre "O feminismo negro” ao Jornal Nexo, Disponível no YouTube (25.jul.18).
} 


\section{4. "NA VOZ DE MINHA FILHA SE FARÁ OUVIR A RESSONÂNCIA O ECO DA VIDA-LIBERDADE"11}

A história da educação para os negros estadunidenses foi marcada, também, pela opressão, pela luta, mas também pelo apoio e intervenções de homens e mulheres brancas. Esse grupo entendia que o acesso à educação era direito de todo ser humano e que a escravidão tornava-se inadequada, também, para as crianças negras. Contudo os opressores entendiam que o acesso à leitura, ao conhecimento seria ferramenta importante para o posicionamento no mundo.

Davis (2016) escreve sobre a busca de escolarização dos negros. Segundo a autora, Frederic Douglas, que agiu secretamente e incessantemente para que essa população tivesse acesso à educação. Frederic Douglas era um escravo que foi retirado de sua mãe aos quatro anos, morou com sua avó e, depois, passou por vários donos até conseguir fugir, aos 16 anos. Iniciou seu processo de alfabetização, mesmo proibido para escravos, através da senhora Sophia, dona de escravos, mas foi interrompido pela oposição do marido, Hugh Auld. No entanto, ele continuou observando a aprendizagem das crianças brancas e acompanhava atentamente as letras dos homens brancos. Lia jornais e todo tipo de livro que tinha acesso, questionando a realidade. Ensinou a ler os escravos com quem convivia e, quando foi alugado para outro senhor, ensinou outros escravos, para que pudessem ler a bíblia. Por muito tempo, suas ações não foram percebidas pelos senhores e, gradativamente, ampliava o número de pessoas interessadas nas aulas. Entretanto, ao descobrirem que os escravos da fazenda e ao redor estavam lendo, os senhores proibiram as aulas.

Com a ajuda de um amigo negro libertado, Frederick Douglas fugiu, chegou a Nova York e, posteriormente, viajou para Massachusetts. Conheceu o abolicionista William Lloyd Garrison, dono do jornal "O libertador" e tornou-se conferencista em prol da libertação dos negros. Aos 23 anos, publicou um livro sobre sua história, fez sucesso e várias edições foram lançadas. Viajou para a Inglaterra onde contou com a ajuda de um grupo que arrecadou dinheiro suficiente para comprar sua liberdade. Frederick Douglas foi um abolicionista

\footnotetext{
${ }^{11}$ Conceição Evaristo, Poemas da Recordação e Outros Movimentos. Poema Vozes-Mulher, 2017, p. 11.
} 
influente, tornou-se intelectual, escritor, orador e pastor da igreja Metodista. Lutou, incansavelmente, pela libertação dos negros, pela justiça e o acesso pleno às instituições.

Negros livres também lutaram para a libertação e educação dos negros e escravos, como Prince hall, que entrou com uma petição em 1787 para que o povo negro tivesse acesso à educação. Como não conseguiu, abriu uma escola em sua casa. Luci Terry Prince, lutou, também, pelo acesso à educação, em 1795, foi a primeira mulher a dirigir-se ao Supremo Tribunal dos Estados Unidos com a exigência de terra para os negros e obteve sucesso.

Quarenta anos depois uma jovem professora branca Prudence Crandall defendeu com firmeza o direito das meninas negras de frequentar sua escola em Cantebury, Connecticut. Crandall persistiu no ensino de alunas negras até ser levada para a prisão por se recusar a fechar a sua escola. (DAVIS, 2016, p. 110).

Margareth Douglas, na Virgínia, criou uma escola para crianças negras. Mirtila Miner, em 1851, iniciou um projeto para estabelecer professoras negras. Ela já havia ensinado para crianças negras em Mississipi. Atuou como mãe de jovens negras que ficaram órfãs e as levou para casa para ensinar-lhes. Angariou fundos e apoio de congressistas. Como se esperava, não foi uma ação pacífica. Para aprender, essas jovens negras enfrentaram insultos, tentativas de incêndios e foram agredidas com pedras por gangues racistas. "Tinham o apoio das famílias das jovens estudantes e de abolicionistas como Harriet Beeche Stowe, que lhes doou uma parte do dinheiro recebidos pela venda de a "Cabana do Pai Tomás". (DAVIS, 2016, p.111). A escola, fundada por Margareth Douglas, foi incendiada por pessoas que se opunham à proposta, porém, mais tarde, a “Miner's Teachers College” integrou-se ao sistema público educacional do distrito de Colúmbia.

Com todos os embates, o acesso à escola foi fator relevante para que os escravos não fossem novamente arrastados para a escravidão. Mesmo sem romper com a desigualdade, a educação permitiu-lhes ampliar a consciência e a inserção política e social. A criação de escolas públicas e privadas, a organização da igreja e dos próprios negros impulsionou o fortalecimento do grupo que conseguiu criar uma rede de lideranças para combater os projetos relacionados à escravatura.

Davis (2016), ao investigar a história da escravidão estadunidense, aponta complexas questões como as opressões de raça, gênero e classe e seus desdobramentos históricos. 
Histórias de sofrimento, denúncia, luta, resistência, vozes dos negros e negras que também romperam os silêncios, penetraram nos espaços privados, sociais, jurídicos e educacionais.

Entrelaçada à abordagem e denúncia na obra "Mulher, Raça e Classe", a autora integra a luta do feminismo negro. Essa luta, efetivamente, se engaja ao combate das estruturas da subalternização feminina, ao enfrentamento do racismo e do sexismo. As abordagens de Ângela Davis sobre as mulheres negras no Século XIX, adentram o Século XX e permanecem potentes no Século XXI. Ultrapassa, portanto, o tempo histórico e territorial de muitas sociedades, já mencionado acima. A questão da mulher apontada por Beauvoir, Perrot, Scott integra, ao mesmo tempo, as lutas feministas no Brasil. Em seu viés étnico-racial, se associa às investigações de Djamila Ribeiro, Sueli Carneiro, Conceição Evaristo dentre outras mulheres e homens que denunciam as desigualdades entre homens e mulheres: as opressões da raça, gênero e classe. Essas ativistas lutam pela justiça e, consequentemente, combatem o racismo, o sexismo e apoio ao movimento feminista.

O caminho percorrido pelas mulheres negras na política, na cultura, na produção de novas análises e questionamentos foi longo, no entanto há muito a caminhar, pois as mulheres são diversas. Múltiplas e singulares são as histórias das mulheres. Os fatores culturais, étnicoraciais e socioeconômicos interferem na trajetória e na história de vida das mulheres, inviabilizando o conceito universalizante de mulher. No entanto, a luta pela dignidade humana, pelo respeito e a não violência deve cada vez mais integrar a narrativa e a ação dos seres humanos.

Como nos ensina Conceição Evaristo (2017), no poema "Vozes-Mulher", que ao mesmo tempo que fala de si, como mulher negra, também narra a história das mulheres negras, do sofrimento sem ocultar a resistência à opressão dos brancos. O sonho dos negros e negras pela liberdade é percorrido pela bisavó que "ecoou lamentos de uma infância perdida."; da avó, que "ecoou obediência aos brancos-donos de tudo", atravessou os labirintos do tempo, abrigou os sonhos da mãe que "ecoou baixinho revolta no fundo das cozinhas alheia" e adentra a história da filha que "se fará ouvir a ressonância o eco da vidaliberdade" (EVARISTO, 2017, p.10-11), pois rompeu barreiras, teve acesso à educação, à liberdade e permanece ecoando nas lutas e conquistas do Século XXI. No entanto, muitas 
vozes precisam ecoar, por isso sua "voz ainda ecoa versos perplexos com rimas de sangue e fome".

\section{REFERÊNCIAS}

BEAUVOIR, Simone. O segundo sexo. Vol. II: A experiência vivida. 50 ed. Trad. Sérgio Milliet. Rio de Janeiro: Nova Fronteira, 1980.

CARNEIRO, Sueli. Enegrecer o Feminismo: A Situação da Mulher Negra na América Latina a partir de uma perspectiva de gênero. 06/03/2011. <Disponível em https://www.geledes.org.br > Acesso em 24. mar. 19. >

DAVIS, Ângela. Mulheres, raça e classe. Trad. Heci Regina Candiani São Paulo: Boitempo Editorial, 2016.

EVARISTO, Conceição. Poemas da recordação e outros movimentos. São Paulo: Malê, 2017.

PERROT, Michelle \& DUBY, Georges. Escrever a História das mulheres. In: História das Mulheres no Ocidente.Vol.I. Tradução Alberto Couto et al. São Paulo: EBRADIL,1990.

PERROT, Michelle. Minha História das Mulheres. Tradução CÔRREA, Ângela M. S. São Paulo: Contexto, 2017.

RIBEIRO, Djamila. Feminismo negro para um novo marco civilizatório. Revista Internacional de Direitos Humanos. SUR 24 - v.13 nº 24 • 99 - 104, 2016

RIBEIRO, Djamila. O que é o lugar da fala? Belo Horizonte: Letramento, 2017.

SCOTT, Joan. Gênero: uma categoria útil de análise histórica. Educação e Realidade. n.16 s. Porto Alegre, jul./dez. 1990, p. 5-22.

Submetido em: 23/08/2019

Aprovado em: 15/10/2019 